\title{
Generalization of the Pecaric-Rajic Inequality in a Quasi-Banach Space
}

\author{
Jianbing Cao \\ Department of Mathematics, Henan Institute of Science and Technology, Xinxiang, China \\ Email: caocjb@163.com
}

How to cite this paper: Cao, J.B. (2017) Generalization of the Pecaric-Rajic Inequality in a Quasi-Banach Space. Advances in Pure Mathematics, 7, 467-471.

https://doi.org/10.4236/apm.2017.79031

Received: March 5, 2017

Accepted: August 27, 2017

Published: August 31, 2017

Copyright $\odot 2017$ by author and Scientific Research Publishing Inc. This work is licensed under the Creative Commons Attribution International License (CC BY 4.0).

http://creativecommons.org/licenses/by/4.0/

\begin{abstract}
In the present paper, we shall give an extension of the well known PecaricRajic inequality in a quasi-Banach space, we establish the generalized inequality for an arbitrary number of finitely many nonzero elements of a quasi-Banach space, and obtain the corresponding upper and lower bounds. As a result, we get some more general inequalities.
\end{abstract}

\section{Keywords}

Pecaric-Rajic Inequality, Dunkl-Williams Inequality, Triangle Inequality, Quasi-Banach Space

\section{Introduction}

Let us first recall some basic facts concerning quasi-Banach spaces and some preliminary results. For more information about quasi-Banach spaces, the readers can refer to [1].

Definition 1 Let $X$ be a linear space. A quasi-norm is a real-valued function on $X$ satisfying the following:

1. $\|x\| \geq 0$ for all $x \in X$ and $\|x\|=0$ if and only if $x=0$;

2. $\|\lambda x\|=|\lambda| \cdot\|x\|$ for all $\lambda \in \mathbb{R}$ and all $x \in X$;

3. There is a constant $K \geq 1$ such that $\|x+y\| \leq K(\|x\|+\|y\|)$ for all $x, y \in X$.

The pair $(X,\|\cdot\|)$ is called a quasi-normed space if $\|\cdot\|$ is a quasi-norm on $X$.

A quasi-Banach space is a complete quasi-normed space.

A quasi-norm $\|\cdot\|$ is called a $p$-norm $(0<p \leq 1)$ if

$$
\|x+y\|^{p} \leq\|x\|^{p}+\|y\|^{p}
$$

for all $x, y \in X$. In this case, a quasi-Banach space is called a $p$-Banach space. 
Let $X$ be a normed linear space. The following is the well known DunklWilliams inequality (see [2]), which states that the for any two nonzero elements $a, b \in X$,

$$
\left\|\frac{a}{\|a\|}-\frac{y}{\|b\| \|}\right\| \frac{4\|a-b\|}{\|a\|+\|b\|}
$$

Many authors have studied this inequality over the years, and various refinements of this inequality (1) have been obtained (see e.g [3] [4] [5]). Pecaric and Rajic [6] got the following inequality in a normed linear space.

$$
\begin{aligned}
& \left\|\sum_{j=1}^{n} \frac{a_{j}}{\left\|a_{j}\right\|}\right\| \leq \min _{i \in\{1, \cdots, n\}}\left\{\frac{1}{\left\|a_{i}\right\|}\left(\left\|\sum_{j=1}^{n} a_{j}\right\|+\sum_{j=1}^{n}\left\|a_{j}\right\|-\left\|a_{i}\right\|\right)\right\}, \\
& \left\|\sum_{j=1}^{n} \frac{a_{j}}{\left\|a_{j}\right\|}\right\| \geq \max _{i \in\{1, \cdots, n\}}\left\{\frac{1}{\left\|a_{i}\right\|}\left(\left\|\sum_{j=1}^{n} a_{j}\right\|-\sum_{j=1}^{n}\left\|a_{j}\right\|-\left\|a_{i}\right\|\right)\right\} .
\end{aligned}
$$

Furthermore, the authors [6] also showed that these inequalities imply some refinements of the generalized triangle inequalities obtained by some authors. For generalized triangle inequalities, note that, some authors have also got many related results (see [7] [8]). In this paper, we shall discuss some extensions of the inequalities (2) and (3) for an arbitrary number of finitely many nonzero elements of a quasi-Banach space.

\section{Main Results}

Note that, given a $p$-norm, the formula $d(x, y):=\|x-y\|^{p}$ gives us a translation invariant metric on $X$. By the Aoki-Rolewicz theorem [9] (see also [1]), each quasi-norm is equivalent to some $p$-norm. Henceforth we can get similar results with $p$-norm. In the following, we first generalize the inequalities (2) and (3) with $p$-norm a $p$-Banach space.

Theorem 2 Let $X$ be a p-Banach space and $a_{1}, \cdots, a_{n}$ nonzero elements of $X$. Then we have

$$
\begin{aligned}
& \left\|\sum_{j=1}^{n} \frac{a_{j}}{\left\|a_{j}\right\|}\right\|^{p} \leq \min _{i \in\{1, \cdots, n\}}\left\{\frac{1}{\left\|a_{i}\right\|^{p}}\left(\left\|\sum_{j=1}^{n} a_{j}\right\|^{p}+\sum_{j=1}^{n}\left\|a_{j}\right\|-\left\|a_{i}\right\|^{p}\right)\right\}, \\
& \left\|\sum_{j=1}^{n} \frac{a_{j}}{\left\|a_{j}\right\|}\right\|^{p} \geq \max _{i \in\{1, \cdots, n\}}\left\{\frac{1}{\left\|a_{i}\right\|^{p}}\left(\left\|\sum_{j=1}^{n} a_{j}\right\|^{p}-\sum_{j=1}^{n}\left\|a_{j}\right\|-\left\|a_{i}\right\|^{p}\right)\right\} .
\end{aligned}
$$

Proof. First, let us prove the inequality (4): for a fixed $i \in\{1, \cdots, n\}$, we have

$$
\begin{aligned}
\left\|\sum_{j=1}^{n} \frac{a_{j}}{\left\|a_{j}\right\|}\right\|^{p} & =\left\|\sum_{j=1}^{n} \frac{a_{j}}{\left\|a_{i}\right\|}+\sum_{j=1}^{n}\left(\frac{1}{\left\|a_{j}\right\|}-\frac{1}{\left\|a_{i}\right\|}\right) a_{j}\right\|^{p} \\
& \leq\left\|\sum_{j=1}^{n} \frac{a_{j}}{\left\|a_{i}\right\|}\right\|^{p}+\sum_{j=1}^{n}\left|\frac{1}{\left\|a_{i}\right\|}-\frac{1}{\left\|a_{j}\right\|}\right|^{p}\left\|a_{j}\right\|^{p}=\frac{1}{\left\|a_{i}\right\|^{p}}\left(\left\|\sum_{j=1}^{n} a_{j}\right\|^{p}+\sum_{j=1}^{n}\left\|a_{j}\right\|-\left\|a_{i}\right\|^{p}\right) .
\end{aligned}
$$


from this it follows that

$$
\left\|\sum_{j=1}^{n} \frac{a_{j}}{\left\|a_{j}\right\|}\right\|^{p} \leq \min _{i \in\{1, \cdots, n\}}\left\{\frac{1}{\left\|a_{i}\right\|^{p}}\left(\left\|\sum_{j=1}^{n} a_{j}\right\|^{p}+\sum_{j=1}^{n}\left\|a_{j}\right\|-\left\|a_{i}\right\|^{p}\right)\right\},
$$

which is the inequality (4). The second inequality (5) follows likewise and the details are omitted.

Now, we generalize the inequalities (2) and (3) with quasi-norm in a quasiBanach space.

Theorem 3 Let $X$ be a quasi-Banach space and $a_{1}, \cdots, a_{n}$ nonzero elements of $X$. Then we have

$$
\begin{aligned}
& \left\|\sum_{j=1}^{n} \frac{a_{j}}{\left\|a_{j}\right\|}\right\| \leq \min _{i \in\{1, \cdots, n\}}\left\{\frac{C}{\left\|a_{i}\right\|}\left(\left\|\sum_{j=1}^{n} a_{j}\right\|+\sum_{j=1}^{n}\left\|a_{j}\right\|-\left\|a_{i}\right\|\right)\right\}, \\
& \left\|\sum_{j=1}^{n} \frac{a_{j}}{\left\|a_{j}\right\|}\right\| \geq \max _{i \in\{1, \cdots, n\}}\left\{\frac{1}{\left\|a_{i}\right\|}\left(\left\|\sum_{j=1}^{n} \frac{a_{j}}{C}\right\|-\sum_{j=1}^{n}\left\|a_{j}\right\|-\left\|a_{i}\right\|\right)\right\} .
\end{aligned}
$$

where $C$ is a constant and $C \geq 1$.

Proof. First, let us prove the inequality (6): for a fixed $i \in\{1, \cdots, n\}$, we have

$$
\begin{aligned}
\left\|\sum_{j=1}^{n} \frac{a_{j}}{\left\|a_{j}\right\|}\right\| & =\left\|\sum_{j=1}^{n} \frac{a_{j}}{\left\|a_{i}\right\|}+\sum_{j=1}^{n}\left(\frac{1}{\left\|a_{j}\right\|}-\frac{1}{\left\|a_{i}\right\|}\right) a_{j}\right\| \\
& \leq C_{1}\left\|\sum_{j=1}^{n} \frac{a_{j}}{\left\|a_{i}\right\|}\right\|+C_{1}\left\|\sum_{j=1}^{n}\left(\frac{1}{\left\|a_{j}\right\|}-\frac{1}{\left\|a_{i}\right\|}\right) a_{j}\right\| \\
& \leq C_{1}\left\|\sum_{j=1}^{n} \frac{a_{j}}{\left\|a_{i}\right\|}\right\|+C_{1} C_{2}\left\|\left(\frac{1}{\left\|a_{1}\right\|}-\frac{1}{\left\|a_{i}\right\|}\right) a_{j}\right\|+C_{1} C_{2}\left\|\sum_{j=2}^{n}\left(\frac{1}{\left\|a_{j}\right\|}-\frac{1}{\left\|a_{i}\right\|}\right) a_{j}\right\| .
\end{aligned}
$$

where $C_{i} \geq 1, i=1,2$. Hence, in order to get the inequality (6), let us set $C=\prod_{j=1}^{n} C_{j}$, where $C_{j} \geq 1$ for all $1 \leq j \leq n$. Thus, from the above inequality it follows that

$$
\begin{aligned}
\left\|\sum_{j=1}^{n} \frac{a_{j}}{\left\|a_{j}\right\|}\right\| & \leq C\left\|\sum_{j=1}^{n} \frac{a_{j}}{\left\|a_{i}\right\|}\right\|+C \sum_{j=1}^{n}\left|\frac{1}{\left\|a_{i}\right\|}-\frac{1}{\left\|a_{j}\right\|}\right|\left\|a_{j}\right\| \\
& =C\left\|\sum_{j=1}^{n} \frac{a_{j}}{\left\|a_{i}\right\|}\right\|+C \sum_{j=1}^{n}\left|\| \frac{a_{j} \|}{\left\|a_{i}\right\|}-1\right|=\frac{C}{\left\|a_{i}\right\|}\left(\left\|\sum_{j=1}^{n} a_{j}\right\|+\sum_{j=1}^{n}\left\|a_{j}\right\|-\left\|a_{i}\right\|\right) .
\end{aligned}
$$

From this it follows that

$$
\left\|\sum_{j=1}^{n} \frac{a_{j}}{\left\|a_{j}\right\|}\right\| \leq \min _{i \in\{1, \cdots, n\}}\left\{\frac{C}{\left\|a_{i}\right\|}\left(\left\|\sum_{j=1}^{n} a_{j}\right\|+\sum_{j=1}^{n}\left\|a_{j}\right\|-\left\|a_{i}\right\|\right)\right\},
$$

which is the inequality (6).

In order to proof the second inequality (7), we proceed in a similar way. For a fixed $i \in\{1, \cdots, n\}$, we get, 


$$
\begin{aligned}
\left\|\sum_{j=1}^{n} \frac{a_{j}}{\left\|x_{j}\right\|}\right\| & =\left\|\sum_{j=1}^{n} \frac{a_{j}}{\left\|a_{i}\right\|}-\sum_{j=1}^{n}\left(\frac{1}{\left\|a_{i}\right\|}-\frac{1}{\left\|a_{j}\right\|}\right) a_{j}\right\| \\
& \geq \frac{1}{C_{1}}\left\|\sum_{j=1}^{n} \frac{a_{j}}{\left\|a_{i}\right\|}\right\|-\left\|\sum_{j=1}^{n}\left(\frac{1}{\left\|a_{i}\right\|}-\frac{1}{\left\|a_{j}\right\|}\right) a_{j}\right\| .
\end{aligned}
$$

where $C_{1} \geq 1$. From this it follows that

$$
\begin{gathered}
C_{1}\left\|\sum_{j=1}^{n} \frac{a_{j}}{\left\|a_{j}\right\|}\right\| \geq \sum_{j=1}^{n} \frac{a_{j}}{\left\|a_{i}\right\|}\left\|-C_{1}\right\| \sum_{j=1}^{n}\left(\frac{1}{\left\|a_{i}\right\|}-\frac{1}{\left\|a_{j}\right\|}\right) a_{j} \| \\
\geq\left\|\sum_{j=1}^{n} \frac{a_{j}}{\left\|a_{i}\right\|}\right\|-C_{1} C_{2}\left\|\left(\frac{1}{\left\|a_{1}\right\|}-\frac{1}{\left\|a_{i}\right\|}\right) a_{j}\right\| \\
-C_{1} C_{2}\left\|\sum_{j=2}^{n}\left(\frac{1}{\left\|a_{j}\right\|}-\frac{1}{\left\|a_{i}\right\|}\right) a_{j}\right\| .
\end{gathered}
$$

where $C_{i} \geq 1, i=1,2$. Hence, in order to proof the inequality (7), let us set $C=\prod_{j=1}^{n} C_{j}$, where $C_{j} \geq 1$ for all $1 \leq j \leq n$. Thus, from the above inequality it follows that

$$
\begin{aligned}
C\left\|\sum_{j=1}^{n} \frac{a_{j}}{\left\|a_{j}\right\|}\right\| & \geq\left\|\sum_{j=1}^{n} \frac{a_{j}}{\left\|a_{i}\right\|}\right\|-C \sum_{j=1}^{n} \mid \frac{1}{\left\|a_{j}\right\|}-\frac{1}{\left\|a_{i}\right\|}\left\|a_{j}\right\| \\
& =\frac{1}{\left\|a_{i}\right\|}\left\|\sum_{j=1}^{n} a_{j}\right\|-\frac{C}{\left\|a_{i}\right\|} \sum_{j=1}^{n}\left\|a_{j}\right\|-\left\|a_{i}\right\| .
\end{aligned}
$$

Thus, from the above inequality we can get

$$
\begin{aligned}
\left\|\sum_{j=1}^{n} \frac{a_{j}}{\left\|a_{j}\right\|}\right\| & \geq \frac{1}{\left\|a_{i}\right\|}\left\|\sum_{j=1}^{n} \frac{a_{j}}{C}\right\|-\frac{1}{\left\|a_{i}\right\|} \sum_{j=1}^{n}\left\|a_{j}\right\|-\left\|a_{i}\right\| \\
& \geq \max _{i \in\{1, \cdots, n\}}\left\{\frac{1}{\left\|a_{i}\right\|}\left(\left\|\sum_{j=1}^{n} \frac{a_{j}}{C}\right\|-\sum_{j=1}^{n}\left\|a_{j}\right\|-\left\|a_{i}\right\|\right)\right\} .
\end{aligned}
$$

This completes the proof.

\section{Conclusion}

In this paper we establish a generalisation of the so-called Pecaric-Rajic inequality by providing upper and lower bounds for the norm of the linear combination $\sum_{j=1}^{n} \frac{a_{j}}{\left\|a_{j}\right\|}$, where $a_{1}, \cdots, a_{n}$ nonzero elements of $X$. Furthermore, we also obtain the corresponding inequalities in a $p$-Banach space with $p$ norm. We should also indicate that when $C=1$ in Theorem 3, the inequalities (2) and (3) can be obtained as a particular case of the results established in Theorem 3. Thus, we get some more general inequalities.

\section{Acknowledgements}

The author is partly supported by the Science and Technology Research Key 
Project of Education Department of Henan Province (No. 18A110018).

\section{References}

[1] Benyamini, Y. and Lindenstrauss, J. (2000) Geometric Nonlinear Functional Analysis. Vol. 1, Volume 48 of American Mathematical Society Colloquium Publications. American Mathematical Society, Providence, 65.

[2] Dunkl, C.F. and Williams, K.S. (1964) A Simple Norm Inequality. The American Mathematical Monthly, 71, 53-54. https://doi.org/10.2307/2311304

[3] Maligranda, L. (2006) Simple Norm Inequalities. The American Mathematical Monthly, 113, 256-260. https://doi.org/10.2307/27641893

[4] Mercer, P.R. (2007) The Dunkl-Williams Inequality in an Inner Product Space. Mathematical Inequalities and Applications, 10, 447-450. https://doi.org/10.7153/mia-10-42

[5] Pecaric, J. and Rajic, R. (2007) The Dunkl-Williams Equality in Pre-Hilbert $C$-Modules. Linear Algebra and its Applications, 425, 16-25. https://doi.org/10.1016/j.laa.2007.03.005

[6] Pecaric, J. and Rajic, R. (2007) The Dunkl-Williams Inequality with $n$ Elements in Normed Linear Spaces. Mathematical Inequalities and Applications, 10, 461-470. https://doi.org/10.7153/mia-10-44

[7] Wu, C. and Li, Y. (2008) On the Triangle Inequality in Quasi-Banach Spaces. Journal of Inequalities in Pure and Applied Mathematics, 9, Art. 41, 4.

[8] Mitrinovic, D.S., Pecaric, J. and Fink, A.M. (2013) Classical and New Inequalities in Analysis (Vol. 61). Springer Science and Business Media.

[9] Rolewicz, S. (1984) Metric Linear Spaces, PWN-Polish Scientific Publishers, Warsaw, D. Reidel Publ., Dordrecht.

\section{Scientific Research Publishing}

Submit or recommend next manuscript to SCIRP and we will provide best service for you:

Accepting pre-submission inquiries through Email, Facebook, LinkedIn, Twitter, etc. A wide selection of journals (inclusive of 9 subjects, more than 200 journals)

Providing 24-hour high-quality service

User-friendly online submission system

Fair and swift peer-review system

Efficient typesetting and proofreading procedure

Display of the result of downloads and visits, as well as the number of cited articles

Maximum dissemination of your research work

Submit your manuscript at: http://papersubmission.scirp.org/

Or contact apm@scirp.org 